\title{
A Ética Da Propriedade Privada Em Murray Rothbard
}

\author{
The Ethics of Private Property in Murray Rothbard
}

\author{
Jóni Cardoso Coelho \\ (Faculdade de Letras da Universidade do Porto, Portugal)
}

\section{Resumo}

O presente artigo é a explicação do argumento de Murray Rothbard sobre as origens filosóficas da propriedade privada, tendo sido fundamentadas em várias ideias diferentes como 1) a aproximação à teoria política de John Locke; 2) uma defesa do jusracionalismo; 3) a defesa da liberdade. A filosofia de Rothbard é composta pela propriedade privada, pelo direito natural, pela teoria predatória do Estado e pela sua visão anarcocapitalista. No entanto, para se entender a filosofia de Rothbard é fundamental discutir a ética da propriedade privada, pois esta ideia é fundamental no seu pensamento político. A metodologia utilizada foi a leitura direta de Murray Rothbard e de vários comentadores sobre diversos tópicos levantados por este autor.

Palavras-chave: Murray Rothbard. Teoria da propriedade. Ética da liberdade. Anarcocapitalismo.

\begin{abstract}
This article is an explanation of Murray Rothbard's argument about the philosophical origins of private property, having been based on several different ideas such as 1) The approach to John Locke's political theory; 2) A defense of jurationalism; 3) The defense of freedom. Rothbard's philosophy is composed by private property, natural law, by the predatory theory of the State and by its anarchocapitalist view. However, to understand Rothbard's philosophy it is essential to discuss the ethics of private property, as this idea is fundamental in his political thinking. The methodology used was a direct reading by Murray Rothbard and several commentators on various topics raised by this author.
\end{abstract}

Keywords: Murray Rothbard. Theory of property. Ethics of freedom. Anarchocapitalism. 


\section{Introdução}

Procuramos desenvolver uma introdução crítica à ética da propriedade privada de Rothbard. As diversas teorias desse economista e filósofo assumem um carácter purista, pois, a propriedade privada é plena, a liberdade é plena, o Estado assume uma premissa imoral e o mercado tem pressupostos jurídicos.

Abordamos a questão da propriedade privada em Rothbard como uma das principais visões filosóficas dele e, porque estão influenciadas pela sua teoria do direito natural.

A teoria da propriedade no pensamento de Rothbard assenta num trabalho essencialmente de filosofia política, na qual se considera a origem da propriedade, os casos onde existe agressão, relativamente à propriedade e aos diversos contextos onde a argumentação do autor falha, porque o seu argumento está desenvolvido por premissas básicas e descura assuntos éticos relevantes, como é uma teoria demasiada simplificada, com exemplos pouco claros. Isto é, um assunto da teoria da propriedade que levanta vários problemas éticos e morais. No entanto, é a visão mais próxima que justifica ou a se aproxima do mercado.

\section{2 Ética da Propriedade Privada em Rothbard}

Rothbard começa por definir o princípio da nãoagressão explicando que nenhum homem ou grupo de homens têm o direito de usar a agressão contra outro ou contra a propriedade alheia, nesee sentido a agressão tem o sinónimo de invasão'. Um libertário defende as

\footnotetext{
${ }^{1}$ ROTHBARD, Murray, Por Uma Nova Liberdade: O Manifesto Libertário. Tradução Rafael de Sales Azevedo, Revisão Fernando Fiori Chiocca e Ágora Filosófica, Recife, v. 21, n. 1, p. 98-120, jan./abr., $2021 \cdot 99$
} 
liberdades civis, como o caso da liberdade de falar, publicar, de reunir ou de se envolver em qualquer crime sem vítima como a pornografia, prostituição ou desvios sexuais. Do mesmo modo, um libertário deseja a propriedade e, que esta não seja violentada ou agredida por uma entidade central ou estatal; o sistema que os libertários adotam é o capitalismo laissez-faire.

“O libertário, em suma, insiste em aplicar a lei moral geral a todos, e não permite isenções especiais a nenhuma pessoa ou grupo" ${ }^{2}$. Nesse sentido, há visões distintas que os libertários defendem, por exemplo David Friedman defende o utilitarismo. No entanto, Rothbard defende a teoria da propriedade e o direito natural, ambos de origem jusracionalista.

Para se chegar ao axioma da não-agressão existem três formas diferentes do ponto de vista ético: 1) a partir da perspetiva emotivista, 2) a perspetiva utilitária; 3) a perspetiva dos direitos naturais ${ }^{3}$. O libertário dos direitos naturais está interessado na justiça no ato e não mudará de posição quando uma determinada lei apenas é boa por estar de acordo com a vontade da maioria (como o caso da visão utilitarista) ${ }^{4}$. A teoria dos direitos naturais está

Tatiana

Villas Boas Gabbi, Instituto Ludwig Von Mises Brasil, São Paulo, 2013, p. 37.

2 Ibidem., p. 38.

3 Ibidem., p. 40.

4 Nas políticas públicas, a teoria dos direitos naturais não tem aplicação, ao contrário da visão utilitarista. Isso não quer dizer que uma teoria seja preferível em relação a outra. Na minha opinião, os direitos naturais acabam por ter uma perspetiva intransigente, fazendo com que quem defende esta posição não admita interferências. Contemporaneamente não tem muitos adeptos. Durante a época medieval e moderna teve vários filósofos que defendiam o direito natural.

100 • Ágora Filosófica, Recife, v. 21, n. 1, p. 98-120, jan./abr., 2021 
fundamentada pela lei natural, sendo resumida porque vivemos num mundo composto por mais de uma "natureza" distinta e, que pode ser investigada pela razão humana. Que se carateriza por aquilo que o indivíduo deve, ao agir, escolher, utilizar os seus próprios meios para atingir os fins desejados 5 . Nesse sentido usar a violência vai contra a natureza humana, pois opõem-se à vontade do homem ${ }^{6}$.

Para elaborar os direitos naturais da propriedade é necessário o estudo da auto-propriedade que se resume assim: "O direito à auto-propriedade assegura o direito absoluto de cada homem, devido a ele (ou ela) ser um ser humano, de ter a "propriedade" de seu próprio corpo; isto é, controlar este corpo livre de qualquer interferência coercitiva"7.

Rothbard distingue por um lado a propriedade que tenha a ver com a produção e as trocas da teoria na qual todos podem controlar uma parcela igual. O direito da

5 Ibidem., p. 42.

${ }^{6}$ Ibidem., p. 42. O problema desta visão é que ao discutir a natureza humana descura qualquer antropologia política. Se o homem fosse bom por natureza, não seria necessária a violência, nesta ideia a violência pode ter um efeito positivo, mesmo que não seja deste modo admitido por Rothbard. Do meu ponto de vista, a posição de Rothbard, falha quando não considera a discussão através da antropologia das paixões, tão presente em filósofos políticos da época moderna como Maquiavel e Hobbes. A dificuldade em admitir que o homem é mau por natureza entra em conflito com a filosofia libertária. Por outro lado, a visão de Rothbard não específica qual a natureza humana. Na ética da liberdade não é assumida qualquer visão realista, na qual se diz o que devemos e não devemos fazer, mas falha enquanto ética, porque não define o que é o bem, o bom ou o justo; falha porque é uma ética apenas com a aplicação à filosofia política, não tendo uma componente intrínseca do estudo ético.

7 Ibidem., p. 42.

Ágora Filosófica, Recife, v. 21, n. 1, p. 98-120, jan./abr., $2021 \cdot 101$ 
auto-propriedade refere-se que cada pessoa tem o direito ao seu corpo e à sua pessoa. O homem não é apenas proprietário do seu corpo, mas dos bens materiais que adquiriu livremente, sem defraudar ou roubar outra pessoa.

$\mathrm{Na}$ discussão que Rothbard ${ }^{8}$ estabelece sobre a propriedade, distingue a propriedade total e a propriedade parcial. O que quer dizer a propriedade plena? O que quer dizer afinal a propriedade parcial? Há duas condições da propriedade: a propriedade universal ou comunista onde todos são iguais; a propriedade parcial que se refere a um grupo em detrimento de outro. Nesse caso (a propriedade parcial) o grupo político $Z$ tem 0 direito a governar todos os não $Z(n Z)$. - Segundo, na propriedade comunista ninguém tem inteiramente 0 direito de propriedade sobre a sua pessoa, nesse caso, uma parte da propriedade pertence a outro (ou outros) indivíduo (s). Essa alternativa é impossível, pois nem todo o mundo controla interruptamente todos os demais, isso quer dizer que é impossível que a propriedade pertença a outros. É limitador considerar que a propriedade é universal ou comunista, visto que têm mais debilidades os sistemas que têm o mercado, por um lado, e o Estado como regulador, por outro. Porém, é preciso ter em atenção que ideias de mercado associadas ao Estado não são um bom exemplo, pois permite que o último tenha um domínio sobre o primeiro? .

8 ROTHBARD, Murray, A Ética da Liberdade, 2a edição, Tradução: Fernando Fiori Chiocca, Revisão Priscila Catão, Instituto Ludwig Von Mises Brasil, São Paulo, 2010, p. 103.

${ }^{9}$ Esta visão está influenciada por uma interpretação na qual o Estado acaba por ter um determinado controlo sobre as vidas as pessoas. No entanto, o controlo também existe por empresas privadas que através 102 • Ágora Filosófica, Recife, v. 21, n. 1, p. 98-120, jan./abr., 2021 
Rothbard ${ }^{10}$ usa o exemplo de Robinson Crusoé, que chegou a uma ilha deserta, usou o seu livre-arbítrio e a sua capacidade para transformar a terra não usada por meio do seu trabalho. Quando chegou outra personagem a essa ilha, Sexta-Feira, ambos trocaram o que produziam $^{11}$. Rothbard não explicita se Crusoé já tinha contato com o mundo exterior antes de ir para a ilha, ou se foi criado em laboratório por um cientista, de modo a poder ir já adulto para essa ilha ${ }^{12}$.

Quando um escultor faz uma obra de arte, quem deveria ser o proprietário da escultura? O seu proprietário pode ser: o escultor da obra de arte; um grupo de homens (diferente do escultor), que a podem expropriar sem o seu consentimento; todos têm o direito a partilhar uma quota

do lóbi e da corrupção conseguem o que querem, manobrando os interesses dos diversos atores institucionais e políticos. Ou seja, uma empresa privada pode-se associar ao Estado para fazer determinados controlos. A discussão que o Estado sempre controla e as empresas permitem, parece-me débil por 1) é verdade que o Estado coage as pessoas a que estas paguem impostos, 2) as empresas podem não coagir diretamente, mas algumas possuem relações estreitas com o poder político; 3) a publicidade e o marketing são formas de persuasão e de certo modo podem sê-lo de manipulação. A perspetiva acima referida chama-se realista, a olhar para os diversos atores políticos e empresariais.

10 Ibidem., p. 105.

${ }^{11}$ Ibidem., p. 105.

12 Podemos pensar em inúmeros contraexemplos para a situação descrita na frase. Os contraexemplos servem para mostrar que a teoria apresentada falha por 1) aceitar acriticamente a visão da propriedade que se aproxima da visão de John Locke; 2) não está imune à crítica, pois depende de um exemplo com os problemas filosóficos inerentes. 
igual de propriedade da escultura como prevê a solução comunista ${ }^{13}$.

A solução apresentada não se encontra explícita no pensamento de Rothbard, porque o escultor pode trabalhar para uma empresa e ter feito um acordo voluntário com a mesma, de modo a saber a quem a obra pertence, ou o escultor pode ser violentado, para que a sua obra seja entregue a outra pessoa, sem o seu consentimento. Se assim for, tal entrega não é legítima, pois estão a agir contra a sua vontade ${ }^{14}$. É a primeira solução que se enquadra na teoria da propriedade que se relaciona com casos como a não-agressão, a liberdade/vontade, a teoria do contrato. Quando um grupo de pessoas decide apropriar-se da obra do escultor, está a usar a violência, ou seja, beneficia-se às custas do expropriado, violando o direito da propriedade. Para Rothbard ${ }^{15}$ a terra tem o mesmo estatuto que as demais propriedades (bens que pertencem a uma pessoa). É o apropriador original que desbrava terras virgens, sem uso e as transforma em propriedade privada. O apropriador é dono da sua propriedade, da mesma maneira que o

13 Ibidem., p. 106. Do meu ponto de vista, Rothbard apenas considera duas formas da obter a propriedade, baseado no comunismo e no capitalismo. Tal é redutor, mesmo as situações capitalistas ou libertárias podem ter graus diferentes, do mesmo modo que noutro sentido contrário há graus diversos. Não estou a alegar que não existe propriedade ou que esta é injusta ou imoral, o problema nesta aceção está com o exemplo dado e as soluções apresentadas.

14 A vontade é uma condição necessária, mas insuficiente, por exemplo aliada à vontade pode estar a necessidade de comer e aí o debate ético tem a ver com a necessidade de comer ou a vontade de trabalhar, deste modo pode existir uma aparente incompatibilidade.

15 Ibidem., p. 108.

104 • Ágora Filosófica, Recife, v. 21, n. 1, p. 98-120, jan./abr., 2021 
comprador que compra a sua casa a outro proprietário atendendo que não o defraudou e cumpriu o contrato.

Existem duas formas para se adquirir a propriedade: produção e a expropriação coercitiva. O homem apenas prospera através da produção e da troca de produtos; o agressor, pelo contrário, é um usurpador da propriedade. Segundo Rothbard a forma coercitiva diminui o rendimento dos produtores e esses irão extinguir-se ${ }^{16}$. O uso da violência ou a atitude parasítica viola a propriedade e o trabalho do produtor, bem como viola o parasita, pois este, em vez de estar a produzir, usa a expropriação para conseguir rendimentos. Para existir violação da propriedade, é necessário que não exista liberdade (por exemplo através da coerção), ou que o contrato seja violado. No entanto, os termos do contrato têm que ser claros para evitar quaisquer litígios. Pode-se pensar no exemplo em que o parasita não se extingue, quando consegue convencer o trabalho do produtor. Nesse sentido, o parasita tem o objetivo de conseguir pessoas para que façam o seu trabalho. A relação entre o parasita e a violação da propriedade é igual à situação que existe entre o Estado e os cidadãos. Nessa aceção, um indivíduo que viola a propriedade de outrem é um criminoso. Um criminoso é alguém que inicia uma agressão contra outra pessoa, ou seja, que usa a coerção para a aquisição dos bens e serviços ${ }^{17}$. O agressor não tem direito a reivindicar a propriedade que adquiriu

\footnotetext{
16 Ibidem., p. 109.

17 Verificar a posição de Albert Jay Nock e de Franz Oppenheimer a este respeito - para uma posição mais sucinta ver Coelho, Jóni, Uma Crítica ao Estado em Murray Rothbard, Dissertação de Mestrado,
} Faculdade de Letras da Universidade do Porto, Porto, 2014. 
através da agressão ${ }^{18}$. Isto é, ninguém tem o direito a agredir o outro para lhe roubar a sua propriedade. Nesse sentido, pode-se usar a violência para recuperar um bem que foi roubado e assim, age-se em legítima defesa. $O$ ato de legítima defesa pressupõe evitar que se fique sem propriedade usando a força física contra o agressor. No entanto, é importante que a violência defensiva não passe para a violência ofensiva, ou seja, deve existir proporcionalidade no ato da legítima defesa. É necessário verificar caso a caso, para se perceber se a legítima defesa não é exagerada e corresponde a um ato de violência em maior grau contra o agressor.

Subsiste outra aplicação da teoria da propriedade referente às terras, visto que elas perduram, praticamente, eternamente. Existe outro problema sobre a propriedade das terras, que é a existência dos bens de capital, dos bens de consumo ou de mercadorias monetárias que foram usadas e transformadas pelo produtor, misturando o seu trabalho, com os recursos naturais ${ }^{19}$. Os bens de capital, os bens de consumo e o dinheiro não existem na natureza, em si mesmo, porque requerem trabalho.

A violação dos direitos de propriedade é considerada uma agressão por parte de $A$ sobre $B$. A solução histórica é fundamental. Essa é uma condição necessária para saber a quem pertence a propriedade, mas é essencial algo mais que uma situação histórica, especialmente em casos injustos. Porém, não é condição suficiente, pois uma situação histórica pode ser injusta por não respeitar a teoria da propriedade. Todo o homem tem

\footnotetext{
18 Ibidem., p. 112.

19 Ibidem., p. 123.

106 • Ágora Filosófica, Recife, v. 21, n. 1, p. 98-120, jan./abr., 2021
} 
direito à sua propriedade e a poder defender-se. Possuir uma propriedade e não a poder defender, equivale a não ter, realmente, essa propriedade na totalidade. Do mesmo modo que todos os proprietários têm o direito de se defenderem ou de contratarem pessoas que o façam. Nesse sentido, uma questão se coloca: até que ponto, ao defender a propriedade, interfiro na propriedade do outro? ${ }^{20}$. Por exemplo: se o João tiver uma loja e se um grupo de amigos decidir boicotar a loja, usando todo o tipo de táticas que não interfiram na propriedade da loja, como usando panfletos ou influenciando as pessoas para que não vão à loja do João, nesse caso, segundo Rothbard, tal seria legítimo ${ }^{21}$. Um dos aspetos que é descurado no pensamento de Rothbard é a responsabilidade pessoal ou individual. Sempre que existe escassez há a possibilidade de conflitos entre os indivíduos, mas para resolver esse problema é através da atribuição dos direitos de propriedade, isto é, através do controlo exclusivo. A solução adotada por Hoppe refere-se aos casos lockianos e rothbardianos ${ }^{22}$. Mesmo nesse sistema de propriedade rothbardiano não existe uma clara definição positiva de propriedade, nem mesmo existe a definição negativa de punição, sendo que, no mesmo prisma, toda a propriedade será privada e todo o crime também será. "Em contraste, aqui argumenta-se que nem toda invasão física implica responsabilidade legal e, mais importante, que algumas ações são passíveis de responsabilização

\footnotetext{
20 Ibidem., p. 137.

21 Ibidem., p. 137.

22 HOPPE, Hans-Hermann, Propriedade, causalidade e responsabilidade legal, 20 de junho de 2016, Disponível em
} http://rothbardbrasil.com/propriedade-causalidade-eresponsabilidade-legal/, Acesso em: 17 set 2016. 
legal mesmo que nenhuma invasão física manifesta ocorra"23.

Por exemplo, existem casos que estando na propriedade de outra pessoa e sendo atingida por um raio, o dono da mesma não é responsabilizado pelo que aconteceu, ninguém é responsável por acidentes que acontecem, mas o seguro e os riscos de acidentes devem ser garantidos individualmente. As pessoas (proprietários) podem ser responsabilizadas ou por ações intencionais ou por negligência. Para alguém ser responsabilizado, terá de existir causalidade, porém, se, chamar o João, e tiver uma armadilha, serei responsável pelo que Ihe venha a acontecer - a menos que, previamente, Ihe explique onde tenho a armadilha e esse fique ciente de todos os riscos que correr.

A violência defensiva deve estar consignada à resistência de atos invasivos contra a pessoa e a sua propriedade, devendo ser considerados dois aspetos: intimidação ou ameaça direta e a fraude que se resume num roubo explícito ${ }^{24}$. A ameaça da agressão deve ser palpável, imediata e diretamente, isto é, deve estar assente num ato evidente. Não se pode comparar um pequeno furto com um assassinato, não possuem o mesmo grau de responsabilização moral e legal ${ }^{25}$. Em diversos casos onde existe roubo de alguma coisa, não está explícita a diferença entre os diversos graus de propriedade. Os diversos graus de propriedade são caraterizados através de uma hierarquia de valores onde se enquadra a vida humana, a inerente liberdade e a

23 Ibidem.

${ }^{24}$ ROTHBARD, Murray, A Ética da Liberdade, Ibidem., 138.

25 Ibidem., p. 141.

108 • Ágora Filosófica, Recife, v. 21, n. 1, p. 98-120, jan./abr., 2021 
propriedade que não apenas o corpo, mas os seus bens (casas, terrenos, praias). Na teoria legal libertária é essencial abordar e definir quais os casos que constituem uma violação mais grave da propriedade. Isto é, o argumento não pode apenas ser econômico, pois são necessárias condições éticas para definir a propriedade. É essencial um estudo do direito libertário e das seguintes condições: onde existe propriedade; o que é violar a propriedade; como julgar quem comete um crime na sociedade libertária; qual a legitimidade em julgar as pessoas que cometem um crime numa sociedade sem Estado.

Há dois sentidos pelos quais os direitos de propriedade são consignados como direitos humanos: o direito à propriedade apenas diz respeito aos seres humanos, tal como o direito ao seu corpo, do mesmo modo que a sua liberdade é entendida como um direito de propriedade. Um aspecto curioso sobre esse assunto refere-se à liberdade de expressão. Rothbard entende que não temos direito à liberdade de expressão, mas existe o direito a arrendar um espaço para falar livremente. 0 mesmo acontece com a imprensa livre, pois todos podem criar o seu próprio jornal e tratar os assuntos que quiserem ${ }^{26}$. No mesmo sentido, o direito à liberdade de expressão não é total e absoluto, pois ninguém tem o direito a gritar, num teatro/cinema, "fogo", quando não existe fogo. Nesse caso, se se gritar "fogo", violam-se os direitos de propriedade dos outros clientes. Esta violação deve-se à ameaça que se efetua sobre as pessoas.

A teoria libertária da propriedade implica o direito de assinar contratos, isto é, trocando os títulos de

26 Ibidem., p. 178.

Ágora Filosófica, Recife, v. 21, n. 1, p. 98-120, jan./abr., 2021 • 109 
propriedade de pessoa para pessoa. O direito do contrato, tal como o direito de propriedade não corresponde a um direito absoluto ${ }^{27}$. Um contrato apenas seria nulo se implicasse o roubo da propriedade, tal é considerado quando os títulos de propriedade já tiverem sido transferidos. É considerado um roubo quando a propriedade é retida pela parte faltosa sem o consentimento do primeiro. Numa sociedade libertária as promessas não são uma transferência de títulos da propriedade. Isto pode ser visto como algo imoral, mas a lei não pode impor a moralidade ${ }^{28}$. Outro aspecto importante é a valorização da liberdade, em oposição a uma servidão involuntária, por exemplo, se alguém quer casar com uma pessoa, prometendo tudo, e no final decide não se casar, não está a romper a lei libertária do contrato. Inclusive quando se quebra a promessa, não é entendida como servidão involuntária, não existindo propriedades sobre promessas ou expectativas. Quebrar uma promessa, pode ser grave do ponto de vista ético, mas a nível da teoria libertária da propriedade, uma promessa não é um contrato com cláusulas específicas.

Poder-se-á fazer um acordo voluntário com o João, na qual obedecerá, para sempre, às decisões que eu quiser, mas se num dado momento decidir "quebrar" o contrato, não se está a desrespeitar qualquer lei libertária, visto que ele tem o pleno direito sobre o seu corpo. Tal acordo, nesse caso, é apenas uma promessa, e forçar uma promessa seria uma coerção. $E$ no caso de rejeitar o acordo com o João, teria de lhe pagar uma

\footnotetext{
27 Ibidem., p. 201.

28 Ibidem., p. 202.

110 • Ágora Filosófica, Recife, v. 21, n. 1, p. 98-120, jan./abr., 2021
} 
indeminização ${ }^{29}$. Não, pois corpo é a é a sua propriedade e o João não tem o direito de violar a propriedade de outra pessoa. Podem existir problemas no consentimento voluntário como a definição da liberdade, não só como ausência de coerção, mas liberdade de atuação, pois qualquer um é livre para não aceitar um trabalho, mas subjetivamente tem de escolher entre aceitar ou continuar numa situação desagradável, estando de acordo com o seu consentimento. Esse suposto consentimento pode sêlo de modo forçado por uma necessidade. Mesmo numa situação de necessidade deve, em primeira instância, refletir o consentimento do agente.

Entendemos a propriedade privada e a apropriação original como ideias convencionais, embora Hoppe as negue, pois acha que não existe alternativa às mesmas ${ }^{30}$. Os direitos de propriedade resultam de uma longa evolução. Ao longo da história déspotas e grupos populares têm tentado limitar, sempre sem sucesso. É impossível qualquer déspota ou grupo popular limitar a propriedade, pois essa começa no corpo da pessoa. Ninguém nessa aceção poderá dispor do seu corpo - uma coisa é fazer algo contra a sua vontade, outra é considerar que o corpo não é a propriedade da pessoa.

\section{Visões Críticas e Elogios às Ética da Propriedade: a Discussão de Vários Comentadores}

O comentador David Gordon ${ }^{31}$, relativamente à ética de Rothbard, entende que a teoria da propriedade é

\footnotetext{
29 Ibidem., p. 204.

30 HOPPE, Hans-Hermann, Propriedade, causalidade e responsabilidade legal, ibidem.

31 GORDON, David, The essential of Rothbard, Ludwig von Mises
} Institute, Auburn, 2007, p. 88-89. 
fundamental, embora sobre a ideia da liberdade dos contratos, este não seja o fim último do pensamento do economista norte-americano, pois a liberdade ilimitada do contrato, longe de ser consequência da auto-propriedade, é o contrário. Quanto a isso, num contrato ninguém se pode vender como escravo. Qualquer um pode submeterse voluntariamente a outra pessoa, no entanto, um contrato legal não implica que se mantenha fiel e submisso, ou seja, o contrato não vale em absoluto. Nenhuma promessa pode ser considerada um contrato ${ }^{32}$, isto é, um contrato implica a transferência de títulos entre as partes, no momento que o mesmo é celebrado. Para Gordon $^{33}$ o aspecto que Rothbard valoriza é a vontade individual. Do nosso ponto de vista, a interpretação da propriedade em Gordon e a posição de Rothbard levantam problemas, pois não levam em consideração as pessoas com diversas doenças que não sejam conscientes. Essa posição apenas é válida para pessoas que livremente, sem qualquer impedimento de saúde ou de outra coisa, tem a liberdade e a vontade.

A comentadora Roberta Modugno ${ }^{34}$ entende que o princípio da não-agressão é, no pensamento de Rothbard, um aspecto central, considerando que ninguém tem o direito a agir contra a vontade de outra pessoa. Esse é o exemplo da atuação estatal, que para um libertário age

\footnotetext{
32 Ibidem., p. 90.
}

33 Ibidem., p. 90.

34 MODUGNO, Roberta, The anarcho-capitalism political theory of Murray N. Rothbard in its historical and intellectual context. Disponível em:

http://austrian-library.s3-website-us-east-

1.amazonaws.com/journals/scholar/Modugno.PDF, Acesso em: 26 mar 2018, p. 10.

112 • Ágora Filosófica, Recife, v. 21, n. 1, p. 98-120, jan./abr., 2021 
contra a vontade das pessoas. O direito de propriedade ${ }^{35}$ (ou propriedade de si mesmo) refere-se ao direito da livre troca. Ao ser humano corresponde não apenas o seu corpo, mas os bens materiais que adquiriu livremente (comprou, foram doados/dados ou encontrou sem recorrer à violência). Portanto, os direitos humanos não se separam dos direitos de propriedade, ou seja, para se usufruir do direito à liberdade de expressão é necessário a existência de direitos de propriedade ${ }^{36}$. Todos os direitos se referem, em última instância, à propriedade, no entanto é necessário delimitar os direitos de propriedade para não abarcar a ideia dos direitos redistributivos, que implica uso da força física para conseguir alguma coisa. A par do direito de propriedade existe o fundamento do princípio de não-agressão. A delimitação da propriedade é através do princípio da não-agressão.

Relativamente ao princípio da não-agressão central na filosofia de Rothbard - esse é considerado como o único princípio moral. A agressão é sempre injustificada. Para o filósofo Matt Zwolinski ${ }^{37}$ há várias razões para criticar o princípio da não-agressão:

a) A poluição, a queima da madeira e o tabagismo afetam o princípio da não-agressão, logo todas essas atividades deveriam ser proibidas por serem implausíveis.

\footnotetext{
35 Ibidem., p. 11.

36 Ibidem., p. 12.

37 ZWOKINSKI Matt, Six reasons libertarian should reject the non-
} agression principle, 8 de abril de 2013, Disponível em: https://www.libertarianism.org/blog/six-reasons-libertarians-shouldreject-non-aggression-principle, Acesso em: 20 mar 2018. 
b) Nenhuma agressão é permitida, por muito pequena que seja, isto é, nenhuma pequena quantidade de benefícios de compensação pode justificar a agressão - o autor justifica essa posição com a existência de impostos para os mais ricos de modo a criar mecanismos de redistribuição, que levarão ao resultado de ajudar as crianças a não morrerem de fome.

c) A possibilidade de cometer algum risco, ou todos cometemos os riscos ou os evitamos. Nesse sentido, tudo o que se faz implica riscos para as outras pessoas.

d) Não se proíbe a fraude, por exemplo, quando existe uma falsificação. Iniciar a agressão para impedir a fraude constitui o início da violência física.

e) Mesmo que essa visão seja a mais correta, os argumentos não chegam, pois é necessário outro princípio, que tem a ver com a propriedade e a quem essa pertence.

f) Se um pai decidir deixar o filho morrer de fome, não está a usar a violência de modo direto, mesmo que nesse sentido se viole a propriedade da criança.

Para Jorge $S_{a n z}{ }^{38}$, há as seguintes razões para rejeitar a posição de Zwolinski: a) responde considerando que não há crimes sem vítima, é necessário saber quem

38 SANZ, Jorge, Contra Matt Zwolinski: seis razones para aceptar el principio de no agresión, 30 de setembro de 2015, Disponível em: http://www.mises.org.es/2015/09/seis-razones-para-aceptar/, Acesso em: 21 mar 2018. 
iniciou a perversidade; b) se alguém ameaça outra pessoa, a resposta passa por usar formas de legítima defesa proporcionais; c) a resposta a esee ponto é que apenas os bens econômicos devem ser outorgados pelas pessoas concretas; d) existe uma relação entre a fraude e a violação do contrato estabelecido, logo a fraude está injustificada no sistema libertário; e) diante disso, quanto aos impostos, o Estado possui poderes e privilégios especiais diferentes das pessoas que votam assim, estaria justificada a ideia de que roubar teria uma determinada razão - por muito pequeno ou insignificante que seja o valor; f) não se deve permitir a morte de ninguém por inanição, embora esse género de problemas deva dizer respeito aos indivíduos, à sociedade, e não ao Estado.

Pudemos destacar, nesta reflexão, o princípio da não-agressão foram apresentados dois tipos de argumentos: primeiro, considerar que existem problemas relativos ao princípio de não-agressão; segundo, justificar que não há problemas na teoria da não-agressão. A justificação da não-agressão deve assentar na definição da teoria da propriedade e nas diversas alternativas, de modo a fortalecer o argumento e pensar nos casos-limite para ver até que ponto esse princípio funciona e, assim considerar a teoria do contrato.

O comentador Edward Feser ${ }^{39}$ distingue três planos na argumentação de Rothbard: a) a fundamentação da sua ética e teoria política poderia ser facilmente desculpabilizada; b) repetiu várias vezes o mesmo argumento ou argumentos similares ao longo de vários

39 FESER, Edward, Rothbard as a philosopher, 25 de abril de 2006, Disponível em:

http://web.archive.org/web/20071014120247/rightreason.ektopos.co m/archives/2006/04/rothbard_as_a_p.html, Acesso em: 19 mar 2018. 
escritos; c) não conseguiu dar bons argumentos filósofos demonstrando o medíocre que é nessa área. O motivo que explica os argumentos serem maus não é por não serem persuasivos, mas por Rothbard não apresentar nenhum argumento minimamente respeitável. O argumento de Feser ${ }^{40}$ contra a propriedade em Rothbard, considera que a propriedade tem apenas duas alternativas. Porém, parece falso, pois pode-se pensar em mais alternativas como: a propriedade que não pertence a ninguém; Deus possui a propriedade de todos; uma classe de pessoas tem apenas direito a uma parcela da propriedade; todos têm propriedade parcial.

Gerard Casey ${ }^{41}$ responde a Feser considerando que o argumento da auto-propriedade é um axioma básico e o primeiro princípio dos libertários. Acha que a questão central no argumento de Rothbard sobre a propriedade se mantém, ou seja, a discussão posterior tem a ver com argumento axiomático. Mesmo que se considere a propriedade como um axioma, ou o primeiro princípio, não é positivamente e diretamente justificado, mas pode receber uma justificação indireta, se entendermos que a negação é uma autocontradição substancial. Para Casey ${ }^{42}$, Rothbard tenta apresentar uma demonstração indireta ou negativa do axioma da auto-propriedade, mostrando os absurdos que levam à sua negação. Feser (segundo Casey ${ }^{43}$ ) entende que Rothbard comete uma falácia formal ao afirmar o consequente, dando um exemplo em que

\footnotetext{
40 Ibidem.

${ }^{41}$ CASEY, Gerard, Fesar on Rothbard as a Philosopher, 8 de agosto de 2006, Disponível em: https://mises.org/library/feser-rothbardphilosopher, Acesso em: 19 mar 2018.

42 Ibidem.

43 Ibidem.
}

116 • Ágora Filosófica, Recife, v. 21, n. 1, p. 98-120, jan./abr., 2021 
isso não acontece: "se supomos que está a chover, o chão está molhado". O chão pode estar molhado não por estar a chover, mas por outra razão (nesse sentido, tem de serem admitidas verdades como "está a chover" e para "o chão estar molhado"). No entanto, termina o seu artigo justificando-se com a posição de Hoppe relativamente à ética da argumentação. A justificação de Casey assenta num intérprete de Rothbard.

Feser ${ }^{44}$, num artigo que crítica a posição de Casey, pensa que Rothbard é um mau filósofo, não por cometer uma falácia lógica, mas porque não é original. No entanto, o argumento de Rothbard sobre a propriedade tem um aspecto central na filosofia política e ética, ou seja, a crítica a esta ideia abala os alicerces da sua teoria a nível filosófico. Outra objeção ao argumento de Rothbard assenta no fato de este não desenvolver um trabalho sério.

Na nossa compreensão e posição, Rothbard é um mau filósofo, devido a sua argumentação teórica sobre os diversos assuntos. Não se trata de concordar com a visão ideológica de um autor, mas com os fundamentos e razões que o levam a defender o que defende. A posição de Casey tenta justificar a visão que Rothbard desenvolve, mas as razões para a defesa da propriedade são débeis por assentarem num critério particular (o da não contradição).

\section{Considerações finais}

A ética da propriedade privada ou meramente

\footnotetext{
${ }^{44}$ FESER, Edward, Rothbard revisited, 23 de agosto de 2009, Disponível em: http://edwardfeser.blogspot.com/2009/08/rothbardrevisited.html, Acesso em: 19 mar 2018. 
definição da propriedade em Rothbard está influenciada por diversos pressupostos diferentes, ou seja, 1) a teoria da propriedade em John Locke, no entanto, nesse último autor parece existir uma aproximação à ideia religiosa; 2) a teoria do direito natural de origem racional (jusracionalismo), no entanto esta filosofia tem o problema de considerar a razão como o instrumento essencial e descura a origem natural do direito (é preferível a visão do jusnaturalista porque estava baseada na filosofia clássica, e não está fundamentada pela razão e pelas limitações que existem neste termo, especialmente epistemológicas); 3) a liberdade e a propriedade assumem o caráter teórico, que se refere a uma função plena, mas na realidade não termos a plena liberdade, mesmo considerando que existe livre-arbítrio tal não é pleno, há fatores sociais, psicológicos que impedem que tal ocorra dessa maneira; a ideia de propriedade, baseada na apropriação original descura os menos aptos ou pessoas com determinadas deficiências, ou seja, essa teoria da propriedade privada parece-nos insuficiente para o propósito que o autor defende.

\section{Referências}

CASEY, Gerard. Fesar on Rothbard as a Philosopher. Disponível em: https://www.mises.org/library/feserrothbard-philosopher. Acesso em: 19 mar 2018.

\section{COELHO, Jóni. Uma Crítica ao Estado em Murray}

Rothbard. Dissertação de Mestrado, Faculdade de Letras da Universidade do Porto, Porto: 2014.

FESER, Edward. Rothbard as a philosopher, 2006, Disponível

em:

http://web.archive.org/web/20071014120247/rightreason. ektopos.com/archives/2006/04/rothbard as a p.html.

118 - Ágora Filosófica, Recife, v. 21, n. 1, p. 98-120, jan./abr., 2021 
Acesso em: 19 mar 2018.

FESER, Edward. Revisited. Disponível em:

http://edwardfeser.blogspot.pt/2009/08/rothbard-

revisited.html. Acesso em: 19 mar 2018.

GORDON, David. The essential of Rothbard. Ludwig von Mises Institute, Auburn, 2007.

HOPPE, Hans-Hermann. La idea de una sociedad de derecho privado. Disponível em:

http://www.miseshispano.org/2011/11/la-idea-de-una-

sociedad-de-derecho-privado/. Acesso em: 20 set 2016.

HOPPE, Hans-Hermann. Propriedade, causalidade e responsabilidade legal. Disponível em:

http://rothbardbrasil.com/propriedade-causalidade-e-

responsabilidade-legal/. Acesso em: 17 set 2016.

MODUGNO, Roberta, The anarcho-capitalism political theory of Murray N. Rothbard in its historical and intellectual context. Disponível em: http://austrianlibrary.s3-website-us-east-

1.amazonaws.com/journals/scholar/Modugno.PDF.

Acesso em: 26 mar 2018.

ROTHBARD, Murray. A Ética da Liberdade. 2. ed. Tradução: Fernando Fiori Chiocca, Revisão Priscila Catão, Instituto Ludwig Von Mises Brasil, São Paulo: 2010.

ROTHBARD, Murray. Por Uma Nova Liberdade: 0 Manifesto Libertário. Tradução de Rafael de Sales Azevedo, Revisão Fernando Fiori Chiocca e Tatiana Villas Boas Gabbi, Instituto Ludwig Von Mises Brasil, São Paulo: 2013.

SANZ, Jorge. Contra Matt Zwolinski: seis razones para aceptar el principio de no agresión. Disponível em: http://www.miseshispano.org/2015/09/seis-razones-paraaceptar/. Acesso em: 21 mar 2018. SWOLINSKI, Matt. Six reasons libertarian should reject 
the non-agression principle. Disponível em: https://www.libertarianism.org/blog/six-reasonslibertarians-should-reject-non-aggression-principle. Acesso em: 20 mar 2018.

Jóni Cardoso Coelho

Faculdade de Letras da Universidade do Porto.

E-mail: joni22@live.com.pt

Submetido: $19 / 05 / 2020$

Aprovado: 15/08/2020 